\title{
O Lugar-Comum Arte-Natureza em Der VollKommene Capellmeister (“O Mestre de Capela Perfeito", 1739), DE Johann MatTheson ${ }^{1}$
}

Mônica Lucas²

\begin{abstract}
RESUMO: O mundo luterano produziu um enorme arcabouço teórico e prático para a composição, interpretaçấo e análise musical. Entre os séculos XVII e XVIII, autores do gênero de escritos que passou a ser conhecido como musica poetica publicaram preceptivas cujas bases teórica, sistemática e terminológica eram emprestadas de retóricas e de poéticas latinas, leituras obrigatórias em todas as escolas luteranas, desde a reforma do ensino, consolidada em 1528, por Martinho Lutero e Philipp Melanchton. Neste artigo, mostraremos como o lugar comum arte-natureza é imitado, a partir de poéticas latinas, em preceptivas musicais setecentistas, em especial, Der vollkommene Capellmeister ("O mestre-de-capela perfeito”, 1739), de Johann Mattheson. Abordaremos os conceitos de natureza e de arte para, em seguida, discutir a relação entre eles e o emprego da tópica arte-natureza, por Johann Mattheson, seja a partir da perspectiva do orador perfeito, seja pela tomada da natureza como modelo da arte. Discorreremos, ainda, sobre a ampliaçấo do conceito de natureza, de modo a incluir também a imitaçáo de autoridades e obras, além da naturalidade como objetivo da arte.
\end{abstract}

PALAVRAS-CHAVE: Musica poética. Johann Mattheson. Arte. Natureza. Retórica musical.

\section{INTRODUÇÁOO}

O mundo luterano produziu um enorme arcabouço teórico e prático para a composição, interpretação e análise musical. Entre os séculos XVII e XVIII, autores do gênero que passou a ser conhecido na época como musica poetica propuseram preceptivas cujas bases teórica, sistemática e terminológica foram emprestadas de retóricas e de poéticas clássicas - em especial a Poética aristotélica, que previa princípios únicos para todas as artes, o Orator e o De Oratore, de Cícero, e a Institutio Oratoria, de Quintiliano, leituras

\footnotetext{
${ }^{1}$ http://dx.doi.org/10.1590/S0101-31732016000500006

${ }^{2}$ Docente de História da Música e História da Ópera no Departamento de Música da Escola de Comunicaçôes e Artes, pesquisadora da Instituição da Musica Poetica; autora de Humor e Agudeza em Joseph Haydn: os quartetos op. 33 (Annablume/Fapesp, 2009). Email: monicalucas@usp.br
} 
latinas obrigatórias em todas as escolas luteranas, desde a reforma do ensino consolidada em 1528, por Martinho Lutero e Philipp Melanchton. ${ }^{3}$

As poéticas musicais luteranas estão compreendidas, em grandes linhas, entre as publicaçóes de Joachim Burmeister (1606) e Johann Nikolaus Forkel (1788). Burmeister foi o primeiro a adotar a terminologia retórica, para descrever procedimentos musicais, fato de que demonstra estar plenamente ciente, quando enfatiza a novitas vocabulorum de suas publicaçóes. Tratados posteriores a Forkel não deixam de lado a orientação poético-retórica, mas, neles, encontrase influência cada vez mais marcante da Estética, disciplina que gradualmente passa a substituir a Retórica como parâmetro de juízo sobre as artes. ${ }^{4}$

Nas oratórias latinas que circularam no mundo humanista, a relação entre arte e natureza se manifesta na forma de lugar-comum, ou seja, uma fonte geral de onde se tiram argumentos e provas para tratar os assuntos. Essa mesma tópica aparece em preceptivas da musica poetica, as quais encontram seus modelos nas preceptivas retóricas latinas.

Neste artigo, mostraremos como o lugar comum arte-natureza é recuperado em poéticas musicais setecentistas, em especial, Der vollkommene Capellmeister ("O mestre-de-capela perfeito", 1739), de Johann Mattheson, sem dúvida, a apresentação mais abrangente e detalhada, dentre o corpus de escritos pertencente a esse gênero literário. Trataremos inicialmente dos conceitos de natureza e de arte; em seguida, abordaremos sua relação e o emprego dessa tópica por Johann Mattheson, seja a partir da perspectiva da confluência entre arte e natureza para a configuraçáo do orador perfeito, seja pela tomada da natureza como modelo da arte. A seguir, discorreremos sobre a ampliação do conceito de natureza, de modo a incluir também a ideia de imitação de autoridades e obras modelares, tratando, por fim, do último aspecto da relação entre arte e natureza: o ideal da naturalidade, compreendido no viés da galanterie.

\section{Natureza e ArTe}

Cícero entende por natureza o conjunto de qualidades necessárias para a fertilidade, na oratória, como boa voz, língua ágil, boa capacidade pulmonar, boa disposição física, agudeza e boa memória (CÍCERO, 1942, I, 25, 113-

\footnotetext{
${ }^{3}$ Para mais informações sobre esse assunto, cf. Lucas (2014).

${ }^{4}$ Para mais informaçōes sobre o assunto, cf. Dammann (1995 [1968]).
} 
114, p. 81). Sem elas - ou seja, sem auxílio da natureza - sustenta Cícero, não será possível alcançar a eloquência.

Em 1594, Cesare Ripa, em Iconologia, “[...] obra útil a todos os estudiosos em geral [oradores, pintores, poetas] para dar forma simbólica àquilo que caiba no pensamento humano", também dá à natureza a estatura de qualidade primeira: para ele, natureza é a fonte que nutre todas as coisas criadas, de que decorre a representação pictórica que ele propóe para o conceito: uma jovem desnuda, com os seios cheios de leite.

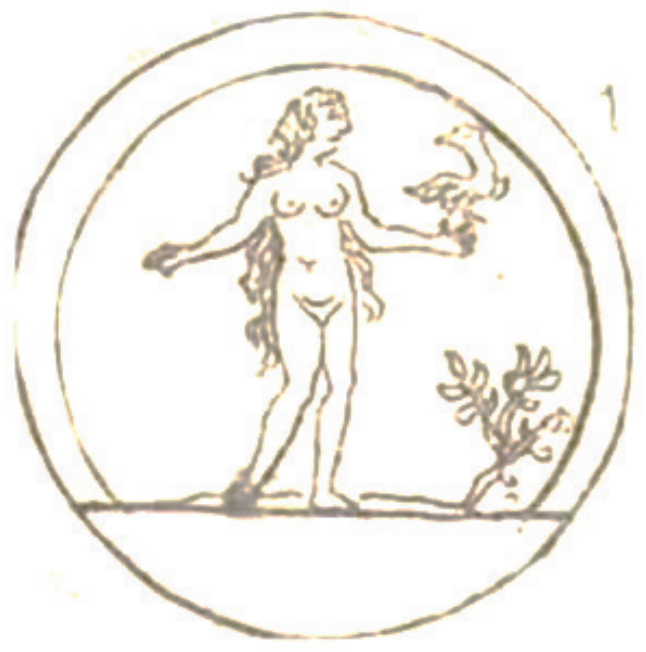

Figura 1: Natureza

Fonte: Ripa (1594, p. 121).

Poéticas musicais setecentistas abordam o lugar arte-natureza com os mesmos argumentos que seus modelos retóricos clássicos e humanistas. Assim, no século XVIII, o flautista Johann Joachim Quantz escreve que a primeira qualidade, na formação do bom músico, é o que ele denomina "talento" ou "dons naturais". As habilidades que Quantz afirma como necessárias para o compositor são, em grande parte, semelhantes às propostas por Cícero: engenho fogoso, alma sensível, boa disposiçáo dos temperamentos, capacidade de imaginação, rapidez de espírito, boa memória (QUANTZ, 1983 [1752], p. 4). ${ }^{5}$

\footnotetext{
5 "Das erste was zu einem, der ein guter Musikus werden will, erfordert wird, ist: ein besonderes gutes Talent, oder Naturgaben. Wer sich auf die Composition legen will, muss einem muntern und feurign Geist, der mit einer zärtlichen Empfindung der Seele verknüpft ist; eine gute Vermischung der
} 
Johann Mattheson, autor de Der vollkommene Capellmeister ("O mestre-de-capela perfeito", 1739), também menciona a precedência dos dons naturais, não alcançáveis pelo esforço nem pela técnica, sobre aqueles ensináveis. É essencial, para o aspirante a mestre-de-capela, possuir aquilo que Mattheson descreve como uma "boa natureza" ou como "impulso e espírito inatos" (MATTHESON, II, 2, 49, p. 106). ${ }^{6}$

Os autores acima citados estão em acordo, tanto ao afirmarem que a natureza é o requisito primeiro e essencial para lograr a excelência artística, quanto por descreverem, de maneira semelhante, quais sejam as habilidades naturais.

$\mathrm{Na}$ constituição do referido lugar-comum, a categoria arte encontrase em oposição à de natureza. Arte constitui a categoria das habilidades passíveis de ensino e apresentaçáo metódica, contrapondo-se aos dons inatos, circunscritos à natureza. Cícero afirma, no livro I do De oratore, que arte constitui uma capacidade definida por princípios claros, bem conhecidos, independentes de toda opiniáo e sujeita à ciência (CICERO, 1942, I, XXII, 109 , p. 77$)^{7}$. Em sentido mais estrito, Cícero dá esse nome ao "[...] conjunto de observaçōes feitas na prática por homens discretos e entendidos, escritas, e, portanto, divididas e classificadas." (CICERO, 1942, I, XXII, 109, p. 77) ${ }^{8}$.

Heinrich Lausberg (1993 [1949], \$28, p. 85-86) retoma o sentido estrito com que Cícero define arte, e descreve-a, no âmbito da retórica, como "[...] um sistema constituído pela experiência que o mestre adquiriu na sua própria criação artística e no ensino de regras doutrinárias [...] ordenadas consequentemente, com o fim de levar a cabo, com sucesso, a realização técnica."

É nesse sentido mais específico que a retórica é entendida como uma arte. Em uma famosa definiçấo de Quintiliano, ela constitui a arte do bem

wogenannten Temperamente, in welchen nicht zu viel Melancholie ist; viel Einbildungs-ErfindungsBeurtheilungs - und Entscheidungskraft; ein gut Gedächniss; ein gutes und zartes Gehör; ein scharfes und fertiges Gesicht; und einen gelehrigen, alles bald und leicht fassenden Kopf, besitzen."

6 "Was [von dem Vorsteher der Musik] erfordert wird, solches lässt sich nicht durch Müh und Fleiss erlangen, wie die andern Eigenschafften, d.i. wo es nicht vorhanden ist, da kömmt es nicht Gaben der Natur sind es, unter dem bekannten Nahmen eines guten Natturels oder angebohrnen Triebes und Geistes."

7 "Ars ita definitur [...] ex rebus penitus perspectis paneque cognitis, atque ab opinionis artibrio seiunctis, scientia comprehensis".

8 "Sin ea [eloquentia], quae observata sunt in usu ac ratione dicendi, haec ab hominibus callidis ac peritis animadversa ac notata, verbis designata, generibus illustrata, partius distributa sunt [...]: non intellego, quam ob rem non [...] ars esse videatur." 
dizer [ars bene dicendi], assunto das preceptivas oratórias. É, ainda, nesse mesmo sentido que o termo é empregado em preceptivas musicais desde o século XIII, em obras que vão desde a Ars cantus mensurabilis ("arte do canto mensurado"), de Franco de Colônia, até o século XVIII, em preceptivas como a Kunst des Reinen Satzes, de Johann Philipp Kirnberger.

É consenso, em obras de orientação retórica, que a perfeição técnica, seja para o orador, seja para o músico, só é passível de ser alcançada através de uma confluência entre natureza e arte. Com respeito a essa opiniáo extensamente repetida em preceptivas retóricas e musicais, Cícero (1986, I, 15) afirma, em defesa do poeta Árquias:

Frequentemente, mais vezes importaram para o louvor da virtude a natureza sem doutrina [arte] do que a doutrina sem a natureza. E posso ainda asseverar o seguinte: quando a distintos e excelentes dons naturais se junta uma certa instruçáo e doutrina, não sei que possa existir de mais preclaro e singular. ${ }^{9}$

Na Institutio Oratoria, Quintiliano (2005, II, 19, 1-2) nos diz, semelhantemente:

Bem sei que ainda se costuma questionar se é a natureza que mais contribui para o orador ou se é a doutrina [arte]. Na verdade, isso nada tem que ver com o propósito da nossa obra, pois um orador sumo náo pode ser feito senáo a partir de ambas [...] Por que se se divorcia uma da outra, a natureza, mesmo sem a doutrina, valerá muito, mas a doutrina nada poderá sem a natureza. ${ }^{10}$

Em Horácio, esse mesmo topos é contemplado do seguinte modo: “[...] tem-se perguntado se um poema se torna digno de louvor pela natureza ou pela arte. Eu náo vejo de que serve o trabalho sem uma veia fértil, nem de que

\footnotetext{
9 "Saepius ad laudem atque uirtutem naturam sine doctrina quam sine natura ualuisse doctrinam! Atque idem ego hoc contendo: cum ad naturam eximiam et ilustrem accesserit ratio quaedam conformatioque doctrinae, tum illud nescio quid praeclarum ac singulare solere exsistere." Cf. ainda De Oratore, I, 79, 91 e 113.

10 "Scio quaeri etiam naturane plus ad eloquentiam conferat an doctrina. Quod ad propositum quidem operis nostri nihil pertinet (neque enim consummatus orator nisi ex utroque fieri potest) [...] Nam si parti utrilibet omnino alteram detrahas, natura etiam sine doctrina multum ualebit, doctrina nulla esse sine natura poterit."
} 
serve o engenho rude; assim uma coisa reclama o auxílio da outra e conspiram amigavelmente." (HORÁCIO, 1994, \$408-411, p. 23). ${ }^{11}$

No Der vollkommene Capellmeister, Mattheson retoma esse lugarcomum e afirma, semelhantemente:

Nascemos com uma disposiçáo do cérebro boa ou má [...]. As pessoas dotadas de imaginação poderosa são capazes de criar muitas boas melodias, mas não havendo reflexão [Nachdenken], não são capazes de compor boas peças. Outras, dificilmente criam melodias de improviso, sem reflexão. As primeiras possuem mais fogo e são verdadeiramente melhores, mas ambas são necessárias na música. (MATTHESSON, 1992 [1739], II, 2, 50-53, p. $106-107){ }^{12}$

Quantz também afirma, a esse respeito: “[...] aquele que se propõe a algo para o qual não tem o dom natural, será, a despeito de toda a boa instrução e de todo o esforço, apenas um músico mediano." (QUANTZ, Einleitung, 6, p. 5) ${ }^{13}$.

Assim, na relação que se constitui entre natureza e arte, a primeira tem a predominância sobre a segunda. Em uma das duas imagens que Cesare Ripa, em Iconologia, propóe para o conceito arte, ela está representada por uma dama que carrega uma tocha na mão esquerda, atestando, com isso, que a arte, semelhantemente ao fogo, é a disposição que molda a natureza.

11 "Natura fieret laudabile carmen na arte, quaesitum est; ergo nec studium sine divite vene ne rude quid prosit vídeo ingenium; alterius sic altera poscit opem res et coniurat amice."

12 "Wir bringen zwar nichts amet uns auf die Welt, als eine gute oder übele Einrichtung des Gehirns [...]. Viele Leute besitzen die Gabe, aus freiem Geiste und stehenden Fusses tausenderley gute Einfäe hervor zu bringen: denn sie sind mit einer starcken Einbildungs-Krafft versehen. [...] Andre [...] haben nicht das geringste Vermögen, etwas [...]ohne Bedenckzeit, zu volsstrecken. Diejenigen, so ihre Gedancken erst mit Fantasiren entdecken [...], weisen das meiste Feuer, und sind dwircklich die allerbesten."

13 "[...] wer sich in der Musik auf etwas leget, wozu er die Gaben nicht hat; der bleibt bey aller guten Anweisung und Bemühung doch nur immer ein mittelmässiger Musikus." 


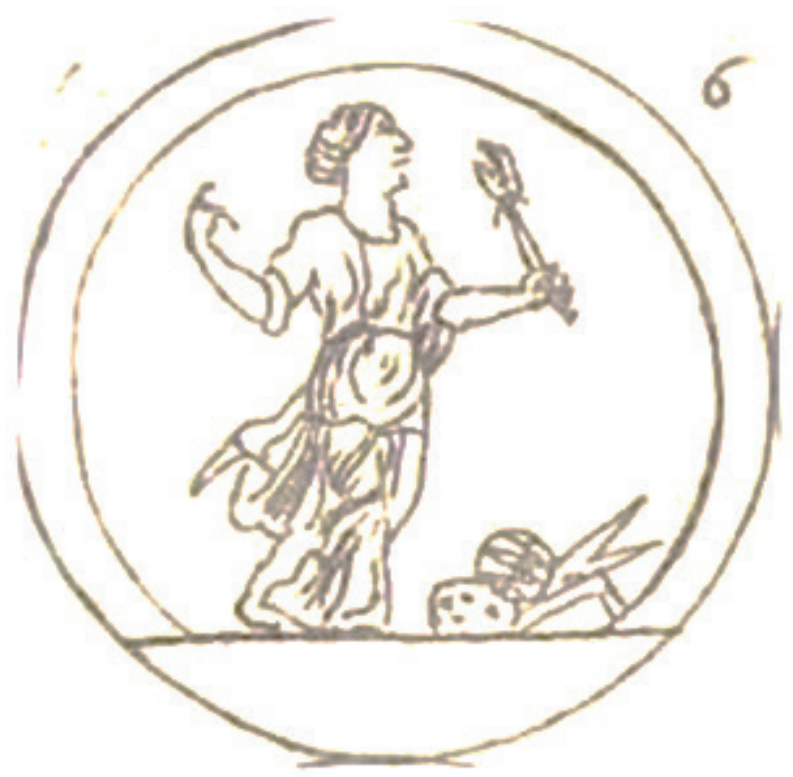

Figura 2: Arte (I).

Fonte: Ripa (1594, p. 215).

Em uma segunda (e mais conhecida) descrição do mesmo conceito, Ripa explica que arte se faz representar por uma figura feminina que segura uma haste fixa na terra, deixando evidente que a arte imita a natureza, conquanto suprida dos defeitos. Na outra mão, a personagem carrega um cinzel e um pincel, o que significa que essa imitação se dá mediante o uso de preceitos técnicos (RIPA, 1993 [1618], p. 37). 


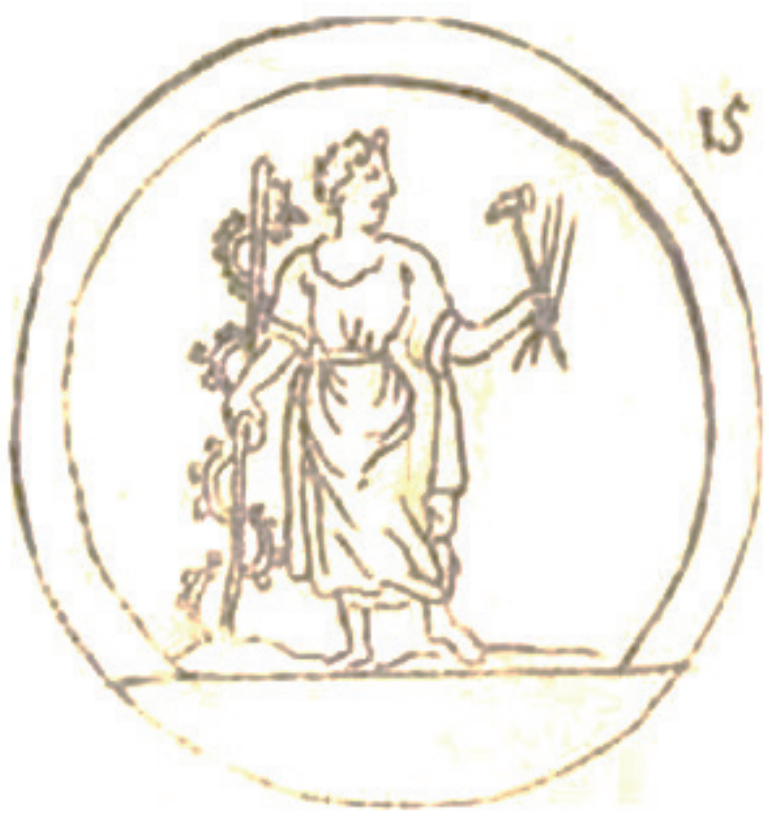

Figura 3: Arte (II).

Fonte: Ripa (1594, p. 11).

Essa mesma relação causal entre as ideias de arte e natureza já está presente em Cícero: ele afirma que a arte apenas pode melhorar o que é naturalmente bom, aguçando e corrigindo eventuais defeitos. A arte, portanto, visa a levar a natureza à sua máxima perfeição.

A tendência da arte ao aperfeiçoamento da natureza justifica as inúmeras obras destinadas a descrever o Orador perfeito, assim como suas emulações humanistas: o Cortesão perfeito, o Músico perfeito etc. Johann Mattheson, no Prólogo de seu O Mestre-de-Capela Perfeito, pronuncia-se do seguinte modo, a respeito dessa questão:

Outras e louváveis obras cumpriram a mesma finalidade: em especial o famoso [Abraham de] Wicquefort e, após este, Cunninga [Timothy Cunningham], descreveram o diplomata perfeito, versado na sabedoria de estado, e aqueles experientes na arte militar souberam discorrer sobre o general perfeito, etc. Sêneca descreve seu sábio estoico; Cícero apresenta o orador perfeito, outros discorrem sobre perfeiçōes distintas, que ainda não surgiram no mundo. [...] Quero também fazer o mesmo, com a ajuda de 
Deus. Não que minha pintura não permita nenhum acréscimo, ou que um mestre-de-capela nunca tenha alcançado o cume mais alto de sua ciência, mas para que possamos estabelecer um objetivo claro. (MATTHESON, 1992 [1739], Vorrede, p. 9). ${ }^{14}$

Ao discorrer sobre as qualidades melódicas, Mattheson retoma a ideia do aperfeiçoamento da natureza pela arte, ilustrando-a com um exemplo: um lapidador pode polir um diamante, mas não pode dar a ele outro brilho que não aquele já dado à pedra pela natureza. Ele acrescenta que "[...] a arte não acrescenta nada à natureza, apenas apresenta-a em sua verdadeira luz, clareando o que antes jazia obscuro." (MATTHESON, 1992 [1739], II, 64, p. 143). ${ }^{15}$

Nessa proposta de relação entre natureza e arte, percebe-se que a arte não apenas aperfeiçoa a natureza, mas toma esta última como seu objeto, imitando-a. Mattheson trata claramente desse assunto: "[...] modelos naturais originam os artísticos. A arte é serva da natureza e a ela remete." (MATTHESON, 1992 [1739], II, V, 15, p. 135). ${ }^{16}$

Entre as obras teóricas setecentistas que defendem a ideia de que a arte imita a natureza, aperfeiçoando-a, Les Beaux-Arts Réduits a un meme Principe (“As Belas Artes reduzidas a um único princípio", 1746), de Charles Batteux, foi certamente aquela que teve maior circulação na Alemanha, seja em traduçóes, seja em comentários, seja no original em francês. ${ }^{17}$ No capítulo referente à música, Batteux salienta que, na arte dos sons, o objeto de imitação

\footnotetext{
14 "In solchen guten Absicht haben auch andre, und zwar löbliche Werke dergleichen Auffschrifft geführet; absonderlich aber des berühmten Wicqueforts, und nach ihm des Cunninga sogenannter volkommene Abgesandter, der in der Staatsklugen Welt bekannt seyn wird, gleichwie die KriegsErfahrnen von ihrem vollkommenen Feldhauptmann zu reden wissen, u. d. g. Seneca gestehet von seinem stoischen Weisen, Cicero von seinem vollkommenen Redner, andre von andern Vollkommenheiten, dass dergleichen noch niemals in der Welt anzutreffen gewesen. [...] Das will ich auch, mit Gottes Hülfe, thun. Nicht, als ob meine Schilderey keinen fernen Zusatz leiden könnte, noch, dass iemals ein Capellmeister den Höchsten Gipfel in seiner Wissenschaft estiegen hätte, oder erreichen werde, sondern, damit man wenigstens ein festes Ziel vor Augen habe, nach welchen einer streben $[\ldots]$ möge."

15 “Unsre Steinschneider können den Diamant poliren. Aber ihm dmit keinen andern glan, kein ander Wasser geben, als was er schon von Natur hat. Die diennbahre Kunst schenckt also der Natur gar keine Schönheit, vermehret sie auch nicht um ein Härlein; sondern stellet sie nur, durch ihr Bemühen, in ein wahres Licht: welches ganz gewiss mehr verdunckelt, als erhellet werden muss, wo eine desporische Kunst zu bestehlen hat."

16 "Natürliche Muster verursachen die künstlichen."

${ }^{17}$ Para mais informaçôes sobre a recepção e comentários à obra de Batteux, na Alemanha setecentista, cf. LUCAS (2010).
} 
não se restringe apenas aos sons da natureza, mas inclui, ainda, as paixões da alma, as quais constituem um material mais rico para imitação do que os simples sons naturais. Dessa forma, a arte musical visa a colocar os afetos em cena, "[...] de maneira ordenada, enfatizada e educada" (BATTEUX, 1770 [1746], III, 3, 3, p. 403), ${ }^{18}$, reafirmando a mesma proposta de Cesare Ripa.

Autores das poéticas musicais alemãs partilham com Batteux a ideia de que os objetos da imitação musical também sejam, além da própria natureza sensível, as paixóes, e que estas últimas sejam objetos mais adequados para a imitação sonora. Assim, seguindo uma tradição já iniciada pelo livro II da Retórica aristotélica, Johann Mattheson dedica um capítulo de seu Der vollkommene Capellmeister à descrição das mesmas: "[...] a invenção e a disposição musicais devem orientar-se pela variedade [dos afetos]", que constituem a natureza da alma (MATTHESON 1992 [1739], I, III, 65, p. 17). ${ }^{19}$

\section{ARTE COMO IMITAÇÁO DE MODELOS}

Nas poéticas do século XVI, o conceito de natureza, como objeto de imitação, amplia-se, passando a incluir, além da natureza sensível e das paixôes da alma, obras e autores canônicos. Muhana, discorrendo sobre esse processo, explica-o da seguinte maneira: "[...] se a poesia é imitação de algo que está na natureza (as açóes humanas), e se na natureza em que o homem existe encontra-se também a poesia como efeito de uma ação humana, imitar na poesia a poesia é imitar a natureza." (MUHANA, 1997, p. 44). O mesmo raciocínio pode ser usado na música: obras musicais, efeitos de paixóes humanas, também integram, segundo esse ponto de vista, o conceito de natureza, logrando, com isso, constituir modelos para imitação.

Desse modo, autores (literários ou musicais) consagrados pela tradição tornaram-se paradigmas para gerações futuras. Seus gêneros, linguagem e estilo foram emulados por muitos artistas. ${ }^{20}$ Essa acepção mais abrangente de natureza como objeto de imitação relaciona-se intimamente ao conceito de estilo, cuja discussão mais extensa, nas poéticas musicais, encontra-se no Der vollkommene Capellmeister. Um escrito mais antigo, Das Neu-eröffnete Orchester

\footnotetext{
18 "Der Ausdruck [der Leidenschaften] wird von der Kunst [...] geordnet, verstärket, ausgebildet." In: Ibid. III, 3, 3, p. 403.

19 "[...] nach derem mannichfälltigen Beschaffenheit [der Affect der Begierde] [...] muss auch die Erfindung und Zuammenfügung der Klänge geordnet werden.”

20 Para mais informaçóes sobre o assunto, cf., ainda, Saltarelli (2009, p. 251-269).
} 
(1713), além de inclui uma primeira versão da exposição sobre estilos, encerra, ainda, um amplo exame sobre os estilos nacionais.

Em O Mestre-de-capela Perfeito, Mattheson revela essa mesma compreensão expandida da natureza como imitação de autoridades. No capítulo em que trata da técnica da imitação como ferramenta compositiva, ele discorre sobre esse conceito, em seu sentido amplo, apresentando três acepçôes do termo:

A música [assim como o diálogo] necessita de argumentos, objeçóes, discussôes e confrontos sonoros, que não se aprendem de maneira melhor do que pela assim chamada Imitação, em sua designação técnica: imitatio, vel potius aemulatio vocum. A imitação tem três sentidos na música: primeiramente, encontramos ocasião para seu emprego em todo o tipo de coisas naturais e inclinaçóes da alma, que são de longe o maior auxílio para a invenção (imitantur res naturales \& animi motus). Em segundo, entendemos por imitaçáo o empenho em imitar o trabalho de um mestre ou compositor (imitatio hujus illiusve auctoris), coisa muito boa, conquanto náo constitua um roubo musical. Em terceiro lugar, entendese por imitação aquela competição pela qual vozes diversas se sobrepóem livremente, constituindo fórmulas, procedimentos ou frases curtas. (MATTHESON, 1992 [1739], III, 15, 3 e 4, p. 331) ${ }^{21}$.

O estudo e a imitação de autores canônicos estão na base do projeto pedagógico das escolas luteranas, ambiente em que se desenvolveu a instituição da musica poetica. ${ }^{22}$ Nesse contexto, Tácito, Sêneca e Cícero são modelos para o estilo da prosa, e Ovídio, Sêneca, Lucano, Marcial, Juvenal, Statius, Claudiano, Virgílio e Horácio, autoridades para o estilo da poesia. Obras

21 "Eine jede Harmonie erfordet [gleichwie eine Unterredung], eben solche Erörterung, einwürffe, Beisprüche und Lustgefechte in den Klängen, die man durch kein bessers Mittel, als durch die so genannte Nachahmung, welche mit ihrem Kunstworte, Imitatio, vel poius Aemulatio vocum heisset, vorstellig machen kan. Diese Nachahmung nun hat in der Music dreierley zu bedeuten. Denn erstlich finden wir Gelegenheit, dergleichen Uiung mit allerhand natürlichen Dingen und GemüthsNeigungen (imitantur res naturales $\&$ animi motus) anzustellen, worin schier das grösseste Hülfsmittel der Erfindung bestehet [...]. Fürs andre wird diejenige Bemühung verstanden, wo na sich gibt, dieses oder jenen Meisters und Ton-Künstlers Areit (imitatio hujus illiusve auctoris) nachzuahmen: welches eine ganz gute Sache ist, so lange kein förmlicher Muikalischer Raug dabey mit unterläufft. Drittens bemercket man durch die Nachahmung denjenigen angenehmen Wettstreit (imitationem moduli vel subjecti cujusdam), welchen verchiedene Stimmen über gewisse Förmelgen, Gänge oder kurze Sätze mit aller Freiheit unter einander führen."

${ }^{22}$ Para uma discussão mais detalhada sobre a recepção de Cícero, na Alemanha luterana, cf. Quadlbauer (1984). 
desses autores referenciais figuram, devidamente selecionadas, em compêndios escolares para uso dos alunos. ${ }^{23}$

Preceptivas da musica poetica também apresentam modelos para imitação. Entre os autores recorrentes, dignos de serem emulados, encontramse, para o estilo antigo do contraponto, Josquin, Ockeghem e Lassus. Mattheson, em Der vollkommene Capellmeister, utiliza como referência para o estilo moderno o estilo italiano, e analisa especificamente uma ária da capo de Benedetto Marcello. Contudo, a discussáo mais extensa sobre modelos de imitação está em Das Neu-Eröffnete Orchestre (1713), em que ele também considera válidos os modelos estilísticos frequentemente citados em preceptivas musicais setecentistas: Jean-Baptiste Lully, para o gosto francês, Arcangelo Corelli, para o italiano, e Reinhard Keiser, para o alemáo ${ }^{24}$. Josquin e Lassus mantêm-se, para Mattheson, como os modelos para o contraponto. Forkel, no fim do século XVIII, é o primeiro a apresentar J. S. Bach como o modelo máximo a ser imitado na música.

O aprendizado desses modelos se dá através do estudo e imitação. No século XVI, as missas feitas à imitação de mestres (também conhecidas modernamente como missas de paródia) constituem um gênero musical claramente construído a partir desse processo. No século XVIII, são conhecidas as transcriçóes de obras italianas feitas por Johann Sebastian Bach, assim como as primeiras peças editadas pelo jovem Mozart, transcrições de sonatas para teclado de Johann Christian Bach. O fundamento dessas transposições é o processo de imitação, base do aprendizado da composição.

$\mathrm{Na}$ retórica, o processo de imitação constitui, tecnicamente, a etapa de treinamento que sucede ao studium (leitura e estudo dos exemplos modelares), sendo, com isso, preparatória para o exercício, propriamente dito, da redação e da elocuçáo (LAUSBERG, 1993 [1949], 470, p. 273). Lucia Marroquin (2008, p. 30) compara o processo de imitação "[...] ao alimento, que, digerido, assimilado e transformado, se renova em cada novo imitador e em cada nova obra."

O processo de imitação é detalhadamente descrito na Ausführliche Redekunst ["Arte abrangente da eloquência”], publicada por Johann Gottsched, três anos antes do Der Vollkommene Capellmeister, de Johann Mattheson. Vale,

\footnotetext{
${ }^{23}$ Para mais referências sobre esse assunto, cf. Lucas (2014).

${ }^{24}$ Mattheson discute os gostos italiano, francês, inglês e alemão, na parte III, 1 de Das Neu-eröffnete Orchestre (1713).
} 
ainda, notar que Gottsched e Mattheson frequentaram os mesmos círculos letrados de Hamburgo e participaram das mesmas academias literárias.

Na segunda parte de seu livro, Gottsched distingue três tipos de imitação: a imitação infantil, que "[...] se preocupa apenas em empregar e utilizar as palavras e maneiras de discursar de bons escritores" (GOTTSCHED, 1973 [1736], II, 2, 1, p. 402), ${ }^{25}$ a imitação viril, "[...] que se preocupa com a maneira de escrita, ou seja, com a ordenação e com a coerência dos pensamentos em várias frases que se sucedem" (II, 2, 1, p. 402), ${ }^{26}$ a imitação oratória, em que "[...] não se imita nem as palavras nem as frases e sua coerência, mas todo o modo e o caráter do discurso, a liberdade dos pensamentos, o amor à verdade, a honestidade da alma, a agudeza na apresentaçấo das ideias." (II, 2, 6). ${ }^{27}$ Para ele, esta última concepção de imitação ultrapassa o âmbito pedagógico e requer um treinamento tal, "[...] que não se pensa mais na imitação, mas se é capaz de escrever e falar como estes escreveram." Gottsched insere a própria Ausführliche Redekunst nesta última categoria: ele se propóe a empresa de seguir as pegadas do grande Tullius [Cícero], trazendo à luz um ensaio sobre a eloquência racional (II, 2, 7).

Como, no processo de imitação, os objetos são diversos, o que importa é saber emular as marcas estilísticas dos modelos selecionados. É esse aspecto da relação entre natureza e arte que permite a consideração e o desenvolvimento do conceito de estilo e, no século XVIII, dos gostos nacionais.

\section{Naturalidade}

O último aspecto da relação entre arte e natureza, abordada neste artigo, é aquela que diz respeito ao conceito de naturalidade, o qual constitui, em preceptivas musicais setecentistas, a finalidade da arte.

Em Institutio Oratoria, Quintiliano já afirma, a propósito da apresentação dos fatos no discurso, que a arte deixa de ser arte, no momento

\footnotetext{
25 "Die kindische [Nachahmung] bemühet sich nur die Wörter und die Redensarten gutter Scribenten nachzuahmen, das ist anzuwenden und zu gebrauchen."

26 "Die andre [männliche Nachahmung] benühet sich die Schreibart das ist die Ordnung und den Zusammenhang der Gedanken in vielen aufeinander folgenden Sätzen nachzumachen."

27 "[Diese ist die oratorische Nachahmung], die weder die Wörter, och die Sätze und ihren Zusammenhang; sondern die ganze Art und den Character der Beredsamkeit, das ist die Freyheit der Gedanken, die Liebe zur Wahrheit, die Ehrlichkeit des Gemüthes, die Munterkei und den Eifer im Vortrage seiner Vorstellungen, nachmachet und auszudrücken suchet."
} 
em que é percebida (QUINTILIANO, 2015, IV, 2, 127). ${ }^{28}$ Esse aspecto da relação entre arte e natureza também está traduzido na sentença ars est celare artem ("a arte está em esconder a arte"), atribuída a Ovídio e frequentemente repetida em preceptivas escolares, no mundo luterano. ${ }^{29}$

Transposta para o âmbito da sociabilidade cortesá no século XVI, a ideia de naturalidade fundamenta o conceito de sprezzatura, amplamente disseminado a partir de Il Corteggiano, o referencial manual de cortesania publicado em 1528, por Baldassare Castiglione. Segundo Castiglione, o cortesão perfeito deve "[...] evitar a afetação, usando uma certa displicência [sprezzatura] que oculte a arte e demonstre que o que se faz e diz é feito sem esforço e quase sem pensar." (CASTIGLIONE, 1997 [1528], I, XXVI). Nessa passagem, os personagens de Castiglione, Canossa e Fregoso, aludem a exemplos de Crassus e Antonius, os principais personagens do De oratore ciceroniano. Castiglione discorre sobre a sprezzatura, mencionando especificamente um exemplo musical: o cortesão deve ocultar os artifícios musicais, de modo que sua interpretação pareça natural. ${ }^{30} \mathrm{~A}$ tópica da sprezzatura é retomada nas obras francesas surgidas sob a égide da galanterie, com a denominação da naturalidade, de onde passa para as preceptivas alemãs. Nessa perspectiva, a naturalidade é a característica mais desejável do homem galante, por evidenciar um decoro perfeito de tempo, lugar e ocasiáo.

A ideia de naturalidade perpassa todo o Der vollkommene Capellmeister: No capítulo dedicado aos estilos musicais, ela aparece da seguinte maneira:

Com a simples palavra natural, no capítulo sobre os estilos foi dito tudo o que concerne à suas qualidades. [Os estilos sacro, teatral e de câmara] necessitam ter como base a essência natural, pois eles devem ser [...] como todo princípio básico: comum, geral e simples. ${ }^{31}$ (MATTHESON, 1992 [1739], 1, 10, 19, p. 71).

\footnotetext{
28 "[...] ad hoc pati non possumus et perire artem putamus, nisi appareat, cum desinat ars esse, si apparet."

${ }^{29}$ Hempfer (1993, p. 2015-2016) mostra que a atribuição dessa passagem a Ovídio (Ars amatoria II, 313) está incorreta; ele recupera o texto da obra original, mostrando as diferenças e levando, ainda, em consideração, o caráter paródico da obra de Ovídio. Contudo, essa questão náo invalida o caráter de lugar-comum galgado pela sentença ovidiana.

${ }^{30}$ Para uma discussão mais aprofundada das implicações ciceronianas no ideal da sprezzatura no Il Corteggiano, cf. Richards (2001).

31 "Mit dem eintzigen Worte, natürlich, wird übrigens in der Abhandlung von Stylen fast alles gesagt, was derem Eigenschafften betrifft, und man bedarff keiner andern Haupt-Abtheilung als in Kirchen, Theatral und Kammer-Styl, so wir sie hier erkläret haben: denn diese müssen dem natürlichen Wesen
} 
Mattheson reitera a ideia de naturalidade em diversos pontos da obra, por exemplo, ao tratar da melodia: "[...] o excesso de arte obscurece a beleza da natureza." ${ }^{32}$ (MATTHESON, 1992 [1739], 2, 5, 15, p. 135).

A ideia de naturalidade permanece válida durante o século XVIII, mesmo a despeito da ruptura do paradigma poético-retórico em prol de uma avaliação das artes guiada por princípios estéticos.

Os principais dicionários musicais publicados na Alemanha no século XVIII e início do XIX, por Johann Walther (Musikalisches Lexikon, 1732) e Heinrich Christoph Koch (Musikalisches Lexikon, 1802), não dedicam verbetes a assuntos como natureza ou naturalidade. Contudo, a enciclopédia sobre as artes publicada por Johann Sulzer, Allgemeine Theorie der Schönen Künste, trata desses dois assuntos e, neles, a ideia de sprezzatura ainda é defendida. Sob a epígrafe natural, lê-se, em Sulzer ( [1774]. p. 3030-3031): “[...] dá-se este epíteto a objetos da arte que parecem se apresentar a nós sem arte, pelo efeito da natureza." 33

O lugar-comum arte-natureza, sob o domínio da ideia de naturalidade, passa da concepção poético-retórica para a estética, ganhando, por conseguinte, novas conotaçóes, as quais podem ser verificadas já em escritos musicais setecentistas, como o Der Critische Musicus, de Johann Adolf Scheibe (1738) ou ainda na Allgemeine Geschichte der Musik ("História geral da música") de Johann Nikolaus Forkel, (1784).

\section{Conclusão}

Este artigo teve como proposta mostrar o alinhamento das ideias de Johann Mattheson com aquelas transmitidas pela tradição poético-retórica. Para isso, mostramos como ideias apresentadas em seu último e mais abrangente escrito, Der vollkommene Capellmeister (1739), emulam proposiçóes que já aparecem em retóricas clássicas.

\footnotetext{
allemahl zum Grunde untergeleget werden, weil sie wircklich, und nach dem innern Zustande der Sache selbst, allgemein d.i. general, und dabei einfach sind, wie ein ieder Grund-Satz seyn muss."

32 "[...] zu viel Kunst benebelt die Schönheit der Natur".

33 "Dieses Beywort giebt man den Gegenständen der Kunst, die uns so vorkommen, als wenn sie ohne Kunst, durch die Würkung der Natur da wären. [...] Das Natürliche ist eine der vorzüglichsten Eigenschaften der Werke der Kunst; weil das Werk, dem es mangelt, nicht völlig das ist, was es seyn soll, und weil diese Eigenschaft schon an sich die Kraft hat, uns zu gefallen. Diese beyden Säze verdienen etwas entwikelt zu werden."
} 
Autores de oratórias latinas estão em acordo, tanto ao afirmarem que a natureza é o requisito primeiro e essencial para alcançar a excelência artística quanto ao descreverem, de maneira semelhante, quais sejam as habilidades naturais. Todos reconhecem que, a despeito da precedência da natureza sobre a arte, a impossibilidade de sistematizar essa primeira qualidade faz com que se concentrem na segunda. Desse modo, preceptivas artísticas visam a fornecer um sistema de regras estabelecido pela experiência que almeja aprimorar aquilo que a natureza apresenta. Mattheson ecoa essa mesma opinião, ao discorrer sobre o mestre-de-capela perfeito.

$\mathrm{Na}$ relação entre natureza e arte, percebe-se que a arte objetiva aperfeiçoar a natureza, tomando-a como seu objeto e imitando-a. No caso da música, Mattheson está em conformidade com outros autores de poéticas musicais, os quais afirmam que os objetos de imitação constituem, além dos sons da natureza sensível, as paixôes, objetos mais elevados para a imitação musical.

Nas poéticas do século XVI, o conceito de natureza, como objeto de imitação, amplia-se, passando a incluir, além da natureza sensível e das paixôes da alma, obras e autores canônicos. Essa acepção mais abrangente do conceito de natureza dá lugar às discussōes sobre estilos e gostos nacionais, assuntos amplamente discutidos por Mattheson.

O último aspecto da relação entre arte e natureza abordada neste artigo é aquela que concerne ao conceito de naturalidade, segundo a qual se recomenda que os artifícios devam ser ocultados, de maneira a evitar a afetação, o que constitui, em preceptivas musicais setecentistas, a finalidade máxima da arte. Nessa perspectiva, Mattheson ainda se alinha com a tradição retórica, uma vez que, para ele, natural é aquilo que se encontra em acordo com os princípios do decoro.

Ao observar a maneira como Mattheson discorre sobre a relação artenatureza, um dos mais importantes lugares-comuns de poéticas e retóricas clássicas, fica evidente, em seu Der vollkommene Capellmeister, a proposta de emulação de autoridades latinas, que não apenas está na base do método de aprendizado setecentista, mas que permite, ainda, revelar Mattheson como um tipo letrado e conhecedor do legado clássico. 
LUCAS, Mônica. The art-nature commonplace in Johann Mattheson's Der vollkommene Capellmeister (The Perfect Chapel Master) by Johann Mattheson. Trans/Form/Ação, Marília, v. 39, p. 75-92, 2016. Edição Especial.

\begin{abstract}
The Lutheran world produced an extensive theoretical and practical framework for musical composition, interpretation, and analysis. In the seventeenth and eighteenth centuries, the authors of what became known as musica poetica published manuals whose systematic, theoretical, and terminological bases were borrowed from Latin rhetorics and poetics (which were required readings in all Lutheran schools after Luther and Melanchthon's reforms of 1528). In this article, we show how the art-nature commonplace was imitated from Latin poetics in eighteenth-century music manuals, especially in Der vollkommene Capellmeister (The Perfect Chapel Master, 1739) by Johann Mattheson. We treat the concepts of nature and art separately, so as to then elucidate the relationship between these concepts and Mattheson's use of the art-nature commonplace, whether from the perspective of the perfect orator or of taking nature as a model of art. We then discuss the expansion of the concept of nature so as to include the imitation of authors and works, and discuss the idea of naturality as the final purpose of art.
\end{abstract}

KEYWORDS: Musica poetica. Johann Mattheson. Art. Nature. Musical rhetorics.

\title{
REFERÊNCIAS
}

BATTEUX, C. Einschränkung der Schönen Künste auf einen einzigen Grundsatz [Les beaux arts réduits en un même principe]. Tradução de Adolf Schlegel. Leipzig; [Paris]: Weidmann, 1770 [1746].

CASTIGLIONE, B. O cortesão [Il cortegiano]. Tradução de C. N. M. Louzada. São Paulo [Venezia]: Martins Fontes [Aldus Manutius], 1997 [1528].

CÍCERO. Em defesa do Poeta Árquias [Pro Archia Poeta Oratio]. Tradução de M. I. R. Gonçalves. Mem Martins: Inquérito, 1986.

CÍCERO. De oratore. Tradução de H. E. Butler. Harvard: Loeb, 1942.

DAMMANN, R. Der Musikbegriff im deutschen barock. Laaber; [Mainz]: Laaber Verlag [Verlag der Akademie der Wissenschaft und der Literatur], 1995 [1968].

GOTTSCHED, J. Ausführliche redekunst. Hildesheim; [Leipzig]: Olms; [Breitkopf], 1973 [1736].

HEMPFER, K. Rhetorik als gesellschaftstheorie: castigliones Il libro del corteggiano. In: KABLITZ, A. Literarhistorische begegnungen: festschrift zum 60. Geburtstag von Bernhard König. Tübingen: Gunter Narr, 1993. p. 103-122.

HORÁCIO. Arte poética [Ars poetica]. Tradução de D. Tringali. São Paulo: Musa, 1994.

LAUSBERG, H. Elementos de retórica literária. Tradução de M. N. Rosado Fernandes. Lisboa; [München]: Gulbenkian; [Hueber], 1993 [1949]. 
LUCAS, M. Aspectos da recepção alemã do 'Les Beaux-Arts réunis a un même Principe', de Charles Batteux (1746). Música em Perspectiva, v.2, n.1, p. 47-67, 2010. Disponível em: $<$ http://revistas.ufpr.br/musica/article/view/19652>. Acesso em: 05 jul. 2016.

LUCAS, M. Emulação de Retóricas Clássicas em Preceptivas da Musica Poetica. Revista Opus, v. 20 n.1, p. 71-94, 2014. Disponível em: <http://www.anppom.com.br/revista/ index.php/opus/article/view/103>. Acesso em: 05 jul. 2016.

MARROQUIN, L. Díaz: la retórica de los afectos. Kassel: Reichenberger, 2008.

MUHANA, A. A epopéia em prosa seiscentista: uma definição de gênero. São Paulo: Editora da UNESP, 1997.

QUADLBAUER, F. Optimus orator. Zu Ciceros Rednerideal und seine nachwirkung. Rhetorica: A Journal on the History of Rhetoric, v.2, n.2, p. 103-119, 1984.

QUANTZ, J. J. Versuch einer anweisung die Flöte Traversiere zu spielen. Leipzig; [Berlin]: VEB Deutscher Verlag für Musik [Voss], 1983 [1752].

QUINTILIANO. Institutio Oratoria. Tradução de B. Bassetto. Campinas: Editora da UNICAMP, 2015.

RICHARDS, J. Assumed simplicity and the critique of nobility: or, how castiglione read Cicero. Renaissance Quarterly, v. 54, n. 2, p. 460-496, 2001. Disponível em: <http:// gracewood0.tripod.com/richardshoby.html>. Acesso em: 28 nov. 2011.

RIPA, Cesare. Der Kunst-Göttin Minerva Liebreiche Enteckung [Iconologia] Augsburg: Kroniger und Göbels Erben, 1704. Disponível em: <http://lartte.sns.it/ripa/Iconologia_ db/dettagli_lettera.php?id=n>. Acesso em: 23 jun. 2016.

RIPA, C. Iconologia. Vicenza; [Padova]: Neri Pozza; [Tozzi], 1996 [1611].

SALTARELLI, T. C. V.L. Imitação, emulação, modelos e glosas: o paradigma da mímesis na literatura dos séculos XVI, XVII e XVIII. Aletria, v.19 n. especial, p. 251-264, 2009.

SULZER, J. G. Natürlich. In: Allgemeine theorie der Schönen Künste. Berlin; [Leipzig]: Directmedia - Digitale Bibliothek, v. 67 [Weidmann und Reich], [1773]. p. 812- 814.

VASCONCELOS, M. B. Á. Ciência do Bem Dizer: a concepção de retórica de Quintiliano em Institutio Oratoria II, 11-21. São Paulo: Humanitas, 2005.

Recebido / Received: 07/06/2016

Aprovado / Approved: 11/08/2016 